\title{
CONSTRUÇÕES COLETIVAS NA FORMAÇÃO MÉDICA SOBRE PLANEJAMENTO EM SAÚDE
}

\author{
CONSTRUCCIONES COLECTIVAS EN EDUCACIÓN MÉDICA SOBRE \\ PLANIFICACIÓN EN SALUD
}

\section{COLLECTIVE CONSTRUCTIONS IN MEDICAL FORMATION ON HEALTH PLANNING}

\author{
Ivana Cristina Vieira de LIMA ${ }^{1}$ \\ Maria das Graças Barbosa PEIXOTO² \\ Laura Pinho SCHWERMANN ${ }^{3}$ \\ Diego Lopez da SILVA ${ }^{4}$ \\ Davi Cesar Gama MAIA ${ }^{5}$
}

RESUMO: Objetivou-se relatar uma experiência de formação médica sobre planejamento em saúde em uma instituição pública estadual de ensino superior. A disciplina foi ofertada no $4^{\circ}$ semestre do Curso de Medicina para 36 estudantes. Houve combinação do ensino tradicional a partir da exposição dialogada com as metodologias ativas de aprendizagem, além de visita técnica a instâncias de planejamento e atividade prática em serviços de saúde. O Google Classroom foi utilizado para comunicação, envio de materiais, postagem de atividades e feedback. As atividades desenvolvidas estimularam a colaboração e o papel ativo na aprendizagem, além de promoverem uma aproximação do contexto vivenciado pelos gestores no âmbito do Sistema Único de Saúde. Enfatizou-se o planejamento estratégico situacional e na importância da prática dialógica na proposição de ações. Esta experiência forneceu subsídios para abordagem do planejamento em saúde na formação médica, oferecendo bases para aplicação do planejamento como ferramenta de gestão.

PALAVRAS-CHAVE: Educação superior. Educação médica. Planejamento em saúde. Sistema único de saúde.

RESUMEN: El objetivo fue reportar experiencia de capacitación médica en planificación en salud en institución pública estatal de educación superior. Disciplina ofrecida en el cuarto semestre del Curso de Medicina a 36 estudiantes. Hubo combinación de enseñanza tradicional, basada en diálogo, con metodologías de aprendizaje activo, y visita técnica a

${ }^{1}$ Universidade Estadual do Ceará (UECE), Fortaleza - CE - Brasil. Docente do Curso de Medicina. Doutorado em Enfermagem (UFC). ORCID: https://orcid.org/0000-0002-2698-9086. E-mail: ivana.maia@uece.br

${ }^{2}$ Universidade Estadual do Ceará (UECE), Fortaleza - CE - Brasil. Docente do Curso de Medicina.

Mestrado em Saúde Pública (UFC). ORCID: http://orcid.org/0000-0002-9800-1778. E-mail: maria.gracas@uece.br

${ }^{3}$ Universidade Estadual do Ceará (UECE), Fortaleza - CE - Brasil. Discente no Curso de Medicina. ORCID: https://orcid.org/0000-0003-4576-7806. E-mail: laura.schwermann@aluno.uece.br

${ }^{4}$ Universidade Estadual do Ceará (UECE), Fortaleza - CE - Brasil. Discente no Curso de Medicina. ORCID: https://orcid.org/0000-0002-0628-5436. E-mail: diego.lopez@aluno.uece.br

${ }^{5}$ Universidade Estadual do Ceará (UECE), Fortaleza - CE - Brasil. Discente no Curso de Medicina. ORCID: https://orcid.org/0000-0002-0525-2739. E-mail: davi.maia@aluno.uece.br 
instancias de planificación y actividad práctica en servicios de salud. El Google Classroom se utilizó para comunicación, envío de materiales, publicación de actividades y comentarios. Las actividades desarrolladas estimularon la colaboración y el papel activo en el aprendizaje, además de promover aproximación del campo experimentado por gerentes en el contexto del Sistema Único de Salud. Se señalaron la planificación situacional estratégica y la importancia de la práctica dialógica en la propuesta de acciones. La experiencia proporcionó subsidios para abordar la planificación en salud en la educación médica, ofreciéndose bases para aplicarla como herramienta de gestión.

PALABRAS CLAVE: Educación superior. Educación médica. Planificación en salud. Sistema único de salud.

ABSTRACT: The goal was to report a medical formative experience on health planning in a state public institution of higher education. The discipline was offered in the fourth semester of the Medicine Course to 36 students. Based on a dialogue-based class there was a combination of traditional teaching and active learning methodologies, as well as a technical visit to areas of planning and practical activity in health services. Google Classroom was used for communication, sending materials, posting activities, and feedback. The activities developed stimulated collaboration and the active role in learning, in addition to promoting an approximation of the context experienced by managers within the scope of the National Health System. Situational strategic planning and the importance of dialogical practice in proposing actions were highlighted. This experience provided support for approaching health planning in medical formation, offering bases for the application of planning as a management too.

KEYWORDS: Education higher. Education medical. Health planning. Unified health system.

\section{Introdução}

A constituição de 1988 estabeleceu os fundamentos legais de um sistema gratuito de saúde para toda a população do Brasil, o Sistema Único de Saúde (SUS). Com ele, novos paradigmas impregnam os princípios e diretrizes que passam a orientar a condução desse importante setor de serviços do país (FUNGHETTO et al., 2015).

Em decorrência disto, surge a necessidade de formar profissionais, alinhados com esses novos paradigmas, capazes de compreender a complexidade do SUS e, consequentemente, de implementar criativamente, ações para melhoria da qualidade desse sistema, contemplando, além do saber técnico-científico, a produção de subjetividade (SILVA et al., 2015; BRASIL, 2003).

A complexidade do SUS exige o planejamento de suas atividades para garantir uma boa gestão dos recursos, humanos e materiais, disponíveis (LACERDA et al., 2013). Dois enfoques de planejamento em saúde podem ser distinguidos: o normativo e o estratégico. 
O planejamento normativo atribui às instâncias superiores do poder a responsabilidade de planejar a política de saúde para uma determinada realidade, caracterizando-se por um enfoque vertical. Concebe os profissionais e usuários do sistema como meros executores do que lhes é indicado a fazer. Como era de se esperar, essa forma de planejamento mostrou-se ineficiente no SUS, pois os indivíduos que vivenciam a realidade local não se identificam com a política de saúde implícita nesse planejamento (GIL; LUIZ; GIL, 2016).

Por sua vez, o planejamento estratégico compreende a saúde na sua dimensão social e, consequentemente, traz para a sua discussão, contextualizada numa determinada realidade local, todos os atores sociais nela inseridos. Assim, o planejamento estratégico consegue diagnosticar a situação da saúde e propor ações para melhorá-la (FENILI; CORREA; BARBOSA, 2017). O planejamento estratégico, ao contrário do normativo, tem se mostrado como uma boa ferramenta para a gestão eficiente do SUS, pois prioriza a participação dos diferentes atores sociais na busca da melhoria do serviço de saúde, em concordância com os princípios e diretrizes do SUS (JUNGES; BARBIANI; ZOBOLI, 2015).

\section{Material e métodos}

Realizou-se um estudo descritivo, do tipo relato de experiência, concernente ao ensino e aprendizagem durante a disciplina Planejamento em Saúde, pertencente à matriz curricular do quarto semestre do Curso de Medicina da Universidade Estadual do Ceará. O Curso foi criado em 2002 e tem como missão promover a saúde no cenário cearense em âmbito individual e coletivo a partir de uma formação médica científica, ética e humanista. $\mathrm{O}$ eixo da Saúde Coletiva integra a matriz curricular do referido Curso e é constituído pelas disciplinas: Introdução à Formação Interprofissional para o SUS; Educação em Saúde; Ciências Sociais; Epidemiologia; Políticas Públicas de Saúde; Planejamento em Saúde; Informação e Avaliação em Saúde.

A disciplina Planejamento em Saúde tem como objetivo abordar o planejamento como tecnologia para a gestão em saúde numa perspectiva de articulação entre racionalidade instrumental e dimensões subjetivas subjacentes aos processos de planejamento em saúde. Possui uma carga horária total de 68 horas, sendo conduzida em 17 aulas no semestre, com duração de quatro horas cada, perfazendo um total de quatro créditos. Foi ofertada no período de dezembro de 2019 a abril de 2020, semanalmente, às quintas-feiras à tarde, por uma equipe multiprofissional composta por cinco professores e uma coordenadora geral. A turma foi 
constituída por 36 discentes. O conteúdo programático da disciplina foi dividido em dois blocos, conforme descrito no Quadro 1.

Quadro 1 - Conteúdo programático da disciplina

\begin{tabular}{|c|c|}
\hline Unidades & Conteúdos \\
\hline $\begin{array}{l}\text { Aspectos teóricos, } \\
\text { conceituais e } \\
\text { metodológicos do } \\
\text { planejamento em saúde }\end{array}$ & $\begin{array}{l}\checkmark \quad \text { O planejamento como tecnologia de gestão: aspectos teórico- } \\
\text { conceituais e operacionais; } \\
\checkmark \quad \text { O planejamento em saúde: evolução histórica e social na América } \\
\checkmark \text { Latina e no Brasil; } \\
\checkmark \quad \text { Enfoques teórico-metodológicos do planejamento em saúde no Brasil } \\
\text { e dimensões do planejamento na estrutura e organização dos serviços } \\
\text { de saúde. }\end{array}$ \\
\hline $\begin{array}{l}\text { Propostas e modelos de } \\
\text { planejamento em saúde }\end{array}$ & $\begin{array}{ll}\checkmark & \text { Sistema de planejamento no SUS: racionalidade instrumental e } \\
& \text { aplicabilidade prática; } \\
\checkmark & \text { Planejamento em saúde: propostas e modelos; } \\
\checkmark & \text { Planejamento e Programação Local em Saúde (PPLS); } \\
\checkmark & \text { Acesso, oferta e demanda no cuidado em saúde: o processo de } \\
& \text { planejamento para atender as necessidades de saúde da população. }\end{array}$ \\
\hline
\end{tabular}

Fonte: Plano de Ensino da Disciplina Planejamento em Saúde

Cada aula era dividida em dois momentos: a) Exposição dialogada sobre o tema do dia; b) Aplicação de metodologia ativa sobre o tema da aula. As estratégias didáticopedagógicas aplicadas durante a disciplina foram: dinâmicas de grupos e exposição dialogada e interativa dos conteúdos programados; discussão e coletivização das observações em grupo, realizadas em sala de aula; leitura programada a partir da busca de textos na internet, bem como dos textos impressos indicados pelos professores; realização de debates com base na metodologia grupo tutorial e discussão de situações-problema relativas ao planejamento em saúde no âmbito do SUS; oficina de treinamento sobre o método Planejamento e Programação Local em Saúde (PPLS); vivência nos serviços de saúde com aplicação do método PPLS junto aos profissionais de saúde, com construção de um relato de experiência.

Os recursos utilizados em sala de aula foram: pincel atômico, quadro branco, computador, datashow, caixas de som, vídeos, quadro branco, folhas de papel madeira, cartolinas, tarjetas, pinceis, roteiros impressos para o desenvolvimento das atividades, textos acadêmicos, jornais e revistas. Também foi criada uma sala virtual criada no Google Classroom para compartilhar notícias, materiais para leitura, plano de ensino e slides das 
aulas. Ademais, esse recurso foi utilizado para receber atividades, emitir nota/feedback das atividades, divulgar a avaliação escrita e a avaliação institucional.

Figura 1 - Página principal do Google Classroom e lista de atividades

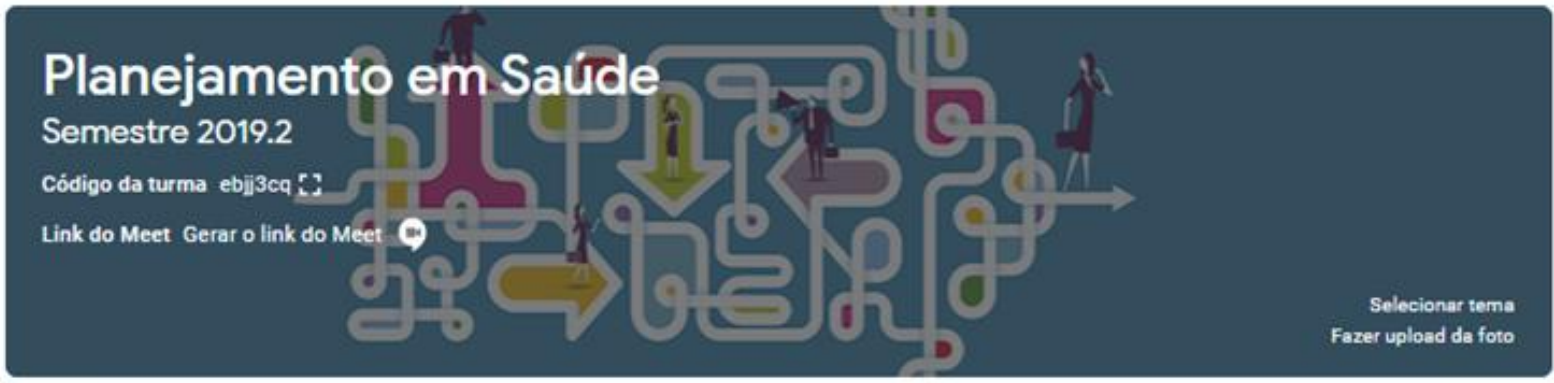

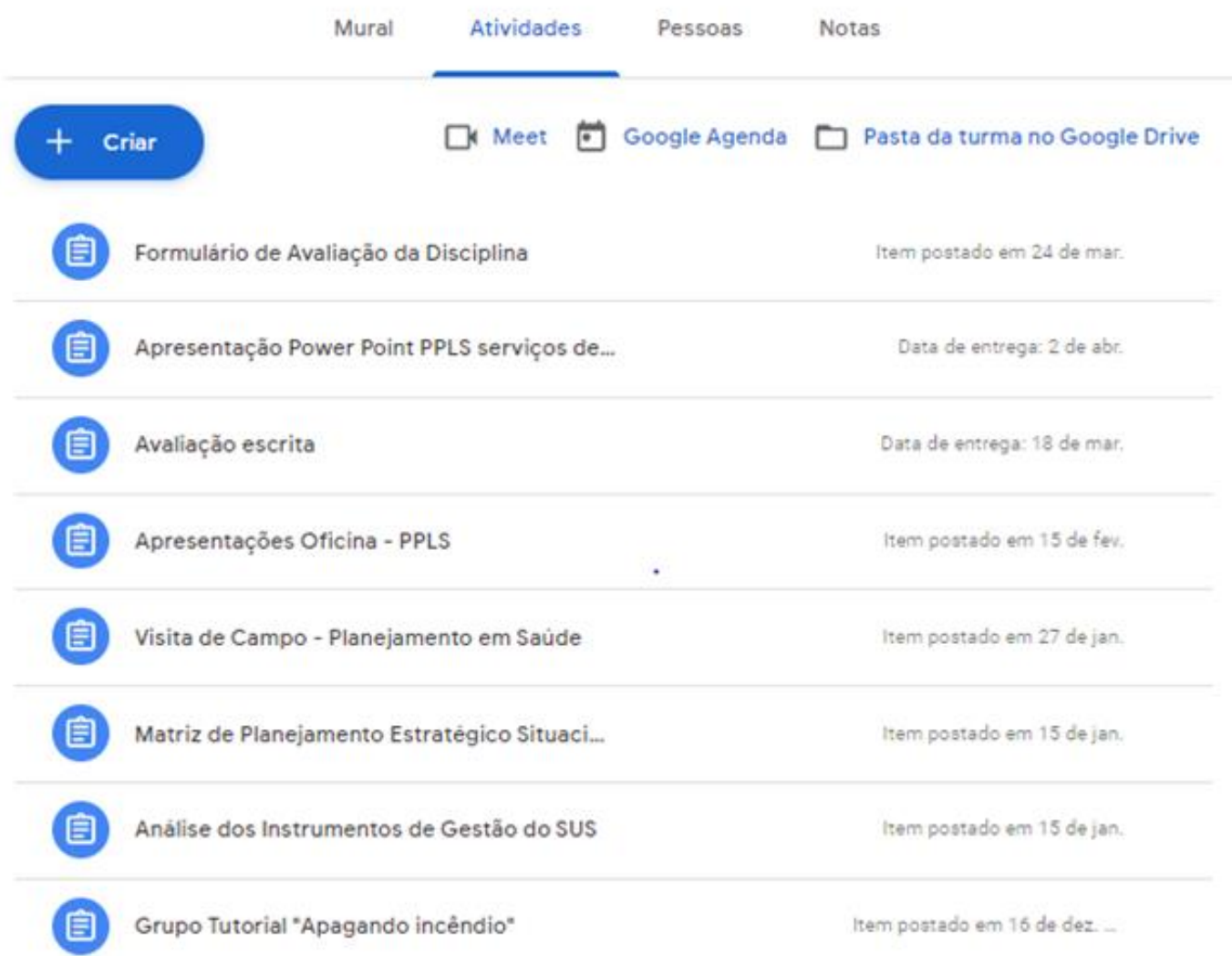

Fonte: Google Classroom

A avaliação do conteúdo apreendido durante a disciplina contemplou a participação individual e coletiva nas várias etapas do processo ensino-aprendizagem, centrando-se na assiduidade, pontualidade, interesse, compromisso e responsabilidade, além dos seguintes critérios: participação nas atividades recomendadas pelos professores (grupo tutorial, atividade de campo e oficina); nota obtida na prova escrita (dissertativa/múltipla escolha); vivência nos serviços de saúde com aplicação de um método junto aos profissionais de saúde, 
com construção de um relato de experiência. A avaliação dissertativa foi aplicada de forma online, a partir de um formulário criado no Google Forms.

Ao final da disciplina realizou-se uma avaliação da satisfação dos estudantes por meio do Google Forms, a qual foi constituída por perguntas objetivas e subjetivas com a finalidade de apreender a percepção dos discentes sobre os métodos de ensino e aprendizagem, os professores e a contribuição para a formação médica, além de captar os pontos positivos, negativos e sugestões.

A finalização da disciplina ocorreu virtualmente a partir de uma reunião realizada na plataforma Zoom. Neste momento, foi apresentado um consolidado das informações captadas pela avaliação da satisfação dos estudantes (organizada no Programa Microsoft Power Point) e, em seguida, os estudantes ficaram livres para expressar opiniões adicionais sobre a disciplina ofertada.

\section{Resultados e discussão}

Na primeira aula da disciplina ocorreu uma apresentação sobre conteúdo programático a ser trabalhado, as estratégicas didático-pedagógicas e a forma de avaliação do desempenho dos estudantes. Além disso, houve o levantamento de expectativas e pacto de convivência. No segundo momento foi solicitado que os estudantes preenchessem um checklist sobre as competências presentes nas Diretrizes Curriculares do Curso de Medicina de 2014 relacionadas à gestão em saúde e planejamento. Em seguida, foi entregue um roteiro para que os estudantes listassem seus objetivos e metas de vida para o ano de 2020. Na sequência, houve a apresentação do vídeo "Qual é a sua visão de futuro?” para debater a importância do planejamento na vida pessoal, com o intuito de alcançar os objetivos. Por fim, a turma foi dividida em trios e foi solicitado que formulassem dois conceitos relacionados ao planejamento e ao planejamento em saúde, a partir do conhecimento prévio acerca desse assunto. Então cada trio compartilhou com a turma os conceitos criados.

As estratégias utilizadas nesta aula introdutória foram relevantes para apreender o conhecimento prévio dos alunos sobre planejamento e associar a disciplina ao cotidiano de vida de cada um, além de promover a sensibilização quanto a importância do assunto trabalhado na disciplina para a futura atuação como médico.

A respeito desse aspecto, evidências apontam a necessidade de a formação médica estar pautada em estratégias que possibilitem uma maior aproximação entre o que se ensina e o que de fato faz parte do cotidiano dos profissionais de saúde em seus campos de trabalho, 
em especial no contexto do SUS, oportunizando a identificação de possibilidades e desafios a serem vivenciados na futura atuação médica (SANTOS JUNIOR et al., 2019).

A segunda aula foi iniciada com a retomada dos conceitos criados na aula anterior a partir de uma apresentação de slides. Em seguida foi realizada uma exposição dialogada sobre o tema Evolução histórica do planejamento em Saúde na América Latina e no Brasil. No segundo momento foi trabalhada uma atividade a partir da metodologia Grupo Tutorial. A turma foi dividida em quatro grupos e cada um ficou responsável por ler uma situaçãoproblema relacionada à problemas, vivenciados na atenção primária e na atenção hospitalar, que envolviam dificuldades na prática do planejamento como instrumentos de gestão. Após a leitura, o grupo teria que cumprir cada um dos sete passos do roteiro do grupo tutorial: passo 1 - Esclarecer termos novos no texto do problema; passo 2 - Definir o problema apresentado no texto; passo 3 - Analisar o problema; passo 4 - Sistematizar a análise e hipóteses de explicação ou solução do problema.; passo 5 - Formular objetivos de aprendizagem; passo 6 Identificar fontes de informação e adquirir novos conhecimentos individualmente; passo 7 Sintetizar o conhecimento e revisar hipóteses iniciais para o problema. Cada grupo tinha como tarefa consolidar os resultados alcançados e organizar uma apresentação em slides para ser apresentada em sala na aula subsequente.

Figura 2 - Apresentações de slides com os resultados do grupo tutorial

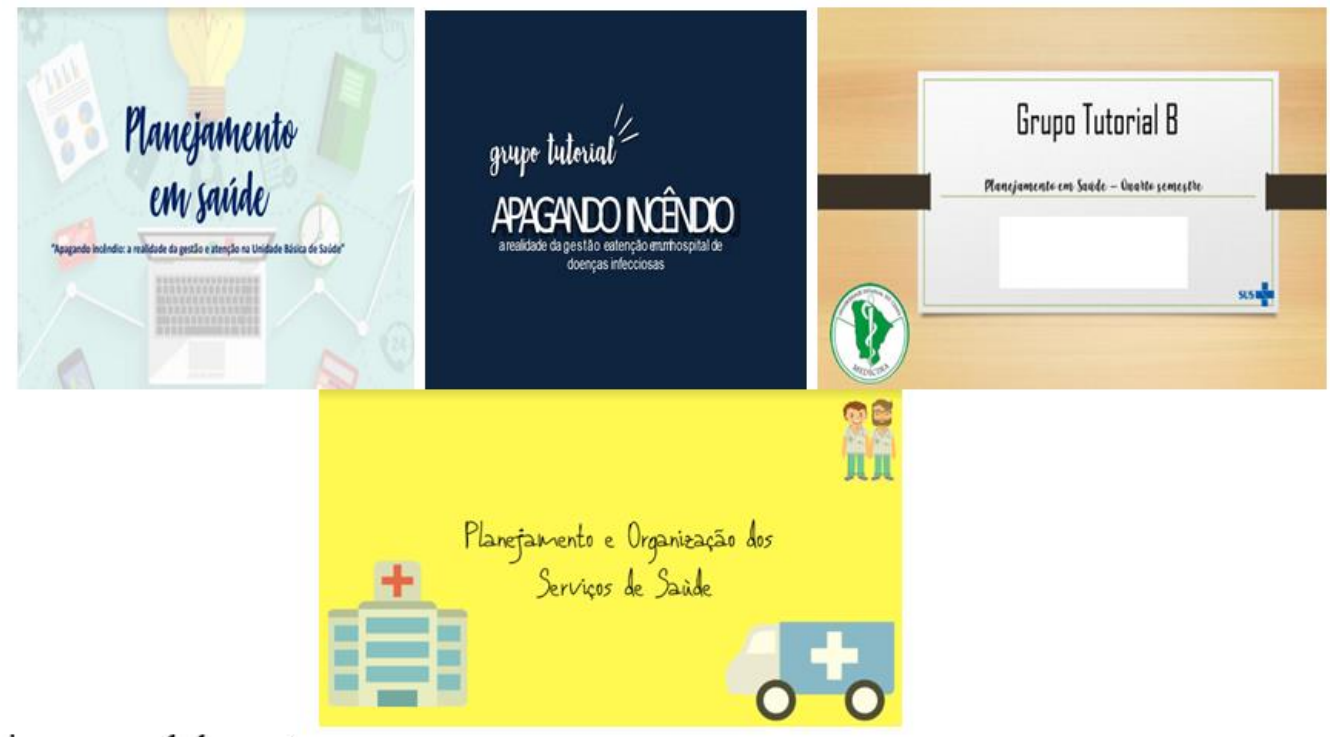

Fonte: Arquivo pessoal dos autores

O grupo tutorial permitiu que os estudantes vivenciassem, a partir de um exemplo no âmbito do SUS, como é utilizar o planejamento na atuação do gestor em saúde. Além disso, a 
discussão dos apontamentos de cada grupo em sala de aula permitiu estimular a reflexão coletiva sobre problemas do processo de trabalho em saúde que poderiam ser contornados se houvesse uma cultura de planejamento em cada um dos cenários propostos.

O método de ensino conhecido como Aprendizagem Baseada em Problemas (PBL Problem Based Learning) utiliza de grupos tutoriais para promover o aprendizado dos alunos através do desenvolvimento de um estudo colaborativo em que os discentes interagem entre si para desenvolver soluções aos problemas a eles apresentados, produzindo neles habilidades sociais de argumentação, socialização, organização e da autonomia da aprendizagem, já os preparando para eventos futuros no mercado de trabalho (MARTINS; FALBO NETO; SILVA, 2018). Ademais, para que haja um bom aproveitamento do que foi estudado, os grupos tutoriais são guiados por tutores, que os ajudam durante a resolução da problemática apresentada.

$\mathrm{Na}$ aula sobre "Planejamento Estratégico Situacional (PES) em saúde: aspectos teórico-conceituais e técnico-operacionais" houve inicialmente uma exposição dialogada para apresentar os elementos centrais do PES e abordar a diferença entre este tipo de planejamento e o planejamento normativo. Após esse momento, a turma foi dividida em quatro grupos e foi entregue para cada grupo um caso clínico que apresentava problemas vivenciados no âmbito da atenção primária em saúde, tais como: adesão à puericultura; uso indiscriminado de benzodiazepínicos; adesão ao tratamento do diabetes; adesão à prevenção do câncer de colo de útero. Além dos casos, cada grupo recebeu uma matriz para identificação dos quatro momentos do PES (momento explicativo, momento normativo, momento estratégico); e momento tático-operacional. Foi solicitado que cada grupo preenchesse a matriz para formulação de um plano de ação para resolução dos problemas listados nos casos. Após esse momento em grupo, os professores receberam cada um dos casos, emitiram um feedback individual que foi enviado via Google Classroom e apresentaram na aula seguinte um consolidado com os principais erros cometidos no preenchimento da matriz. Dentre os erros cometidos estavam: dificuldades na priorização dos problemas; falta de coerência entre as informações preenchidas em cada um dos momentos; superficialidade na apresentação das causas do problema principal; identificação incompleta do prazo para as operações; operações genéricas que não resolviam o problema principal elencado.

Essa atividade foi importante para fixar de forma prática os momentos do PES e para treinar a redação dos pontos chaves de cada um desses momentos. O feedback individual e coletivo emitido pelos professores ajudou toda a turma a identificar os erros cometidos e as mudanças necessárias. 
O PBL já é aplicado no ensino médico desde a década de 1960, tendo como seu fundador Howard Barrows. Esse método tem como metodologia de ensino a aprendizagem autônoma através da introdução de problemas aos discentes e da inserção destes em situações reais para que deem resolução ao problema proposto (GOMES; BRITO; VARELA, 2016). Além disso, a interação aluno-professor, mesmo perdendo o antigo caráter unidirecional de conhecimento, ainda existe, sendo o feedback do professor de grande apreço para a evolução dos alunos, uma vez que ele permite a correção de erros na resolução e indicação de possíveis caminhos a serem tomados (GOMES; BRITO; VARELA, 2016).

$\mathrm{Na}$ aula subsequente foi trabalhado o conteúdo "PlanejaSUS: racionalidade normativa, instrumental e aplicabilidade prática". Do mesmo modo das aulas anteriores, iniciou-se com uma exposição dialogada com o objetivo de apresentar os princípios e diretrizes normativas do planejamento no SUS, bem como os principais instrumentos de apoio para o planejamento no SUS (Plano Municipal de Saúde, Programação Anual de Saúde, Relatório Anual de Gestão e Relatório Detalhado do Quadrimestre Anterior). Essa aula foi ministrada no laboratório de informática. No segundo momento da aula, os alunos foram divididos em duplas e tiveram que realizar no computador uma atividade direcionada à análise da estrutura dos principais instrumentos de apoio para o planejamento no SUS. Para tanto, foram previamente postadas instruções no Google Classroom contendo o Plano Municipal de Saúde de Fortaleza-CE (2018-2021); a Programação Anual de Saúde de Fortaleza-CE (2018) e o Relatório Anual de Gestão de Fortaleza-CE (2017). Além desses instrumentos, foi postado um roteiro de análise composto por itens com opções de respostas dicotômicas "sim" ou "não". À medida que cada um dos grupos entregava o roteiro preenchido, os professores emitiam o feedback.

Essa atividade foi importante para compreender na prática como os instrumentos de gestão são criados e qual é a sua estrutura básica. Tendo em vista que é cada vez mais comum os médicos assumirem atividades de gestão da atenção primária e hospitalar no âmbito municipal, torna-se importante conhecer na prática esses instrumentos. Isso permite visualizar de uma maneira mais próxima do real os indicadores econômicos, demográficos, epidemiológicos e sanitários em nível local, a compreender como ocorre o planejamento ascendente e integrado no SUS e a refletir sobre o impacto financeiro das receitas e despesas disponíveis, bem como ações que deverão ser realizadas para prestação de contas.

$\mathrm{Na}$ aula sobre o Planejamento Estratégico no âmbito municipal e estadual os estudantes foram divididos em grupos e tiveram que realizar uma atividade de campo constituída por uma visita técnica a instâncias municipais e estaduais de planejamento em nível hospitalar (Hospital Santa Casa de Misericórdia, Hospital Geral de Fortaleza, Hospital 
São José de Doenças Infecciosas, Hospital Universitário Walter Cantídio) e da atenção básica (Coordenadoria Regional de Saúde). Nesta visita, os estudantes teriam que realizar uma entrevista com informantes chaves sobre como ocorria o planejamento na referida instância, a qual foi guiada por um roteiro de perguntas. Esse roteiro continha informações sobre: estrutura Organizacional do setor de planejamento; desenvolvimento do processo de planejamento; aspectos restritivos e facilitadores do processo de planejamento. Na aula subsequente cada grupo realizou um relato da experiência da visita técnica para a turma.

Essa atividade permitiu desenvolver nos alunos um senso crítico sobre as facilidades e dificuldades enfrentadas no planejamento em âmbito municipal e estadual. A partir da análise da instância de planejamento investigada, os estudantes fizeram apontamentos sobre a importância do trabalho em equipe e da integração para a efetividade do planejamento, o distanciamento entre as ações planejadas e efetivamente cumpridas, bem como puderam vivenciar a importância do planejamento para melhorar a qualidade da assistência em saúde no âmbito hospitalar.

Os discentes observaram que o desconhecimento e a desvalorização da importância do planejamento para o bom funcionamento dos serviços de saúde por parte dos membros da organização ou da instituição, assim como a falta de compreensão sobre a necessidade de participação de todos os profissionais nas decisões de gestão, foram mencionados como entraves vigentes para que seja aplicado o planejamento. Somados a esses aspectos, os conflitos de ideias e a carência de ferramentas disponíveis para a execução de estratégias também foram relatados como fatores de distanciamento para o alcance de uma cultura de planejamento. Um relato de experiência sobre a aplicação de oficinas de planejamento em saúde em um Curso de medicina no Amazonas demonstrou a importância de trabalhar esse tema para formar profissionais aptos a reconhecer problemas e criar propostas de intervenção em saúde pública (SILVA; RAMALHO; SOUZA, 2018).

Nas três aulas subsequentes foi realizada uma oficina para trabalhar na prática como é realizado o Planejamento e Programação Local em Saúde (PPLS), um modelo de plano de ação idealizado pelo Ministério da Saúde (2004) que tem como base os momentos do PES, o qual viabiliza a sistematização, a identificação e a priorização de problemas, possibilitando o delineamento e a operacionalização de ações estratégicas.

Inicialmente houve uma exposição dialogada para apresentar os cinco passos do método: identificação e formulação do problema (planilhas 1A e 1B); priorização dos problemas (planilhas 2A e 2B); explicação dos problemas (planilha 3); definição de objetivos, ações e análise de viabilidade (planilhas 4 e 5); elaboração da programação operativa 
(planilha 6); acompanhamento e avaliação da programação operativa (planilha 7). Em seguida a turma foi dividida em quatro grupos com o intuito de vivenciar na prática cada um desses momentos com o auxílio de um professor mediador. Foi sugerido que os alunos analisassem e escolhessem pelo menos um problema vivenciado no cotidiano acadêmico para debate. Foram utilizados como recursos na oficina planilhas em papel madeira, tarjetas e pinceis atômicos de cores variadas. Ao final dos três dias de discussão, cada equipe teria que realizar uma apresentação em slides sobre os resultados da oficina.

Os problemas escolhidos pelos grupos para aplicação dos passos do PPLS foram: dificuldades na gestão das atividades pessoais e acadêmicas dos alunos do Curso de Medicina da UECE; carência de capacitação para produção de trabalhos científicos dos alunos do Curso de Medicina da UECE; carga horária excessiva das disciplinas para os acadêmicos de Medicina da UECE; incipiência da gestão pedagógica do Curso de Medicina da UECE. Recomendou-se que os próprios alunos se responsabilizassem pelas ações idealizadas no plano de ação.

Vivenciar os momentos do PPLS permitiu que todos os estudantes atuassem como atores importantes na concepção do plano de ação, fez da sala de aula um local para dar voz aos problemas vivenciados no cotidiano acadêmico, ampliando as perspectivas sob o prisma de diversos olhares e colocando o estudante em uma posição ativa na proposta de resolução do problema identificado. Não houve conflitos neste processo de concepção do plano de ação, fato que possibilitou uma construção coletiva satisfatória do plano de ação.

A aplicação do PPLS na gestão de medidas de intervenção tem-se mostrado útil no que tange à organização e programação, permitindo a elaboração de uma linha de atividades de forma satisfatória. Uzêda et al. (2017) exemplifica a utilização dessa metodologia de planejamento como meio efetivo de racionalização das atividades desenvolvidas para diagnóstico e prevenção da dengue, sendo essencial para o sucesso das experiências dos estudantes envolvidos nas ações em conjunto com o Núcleo de Apoio à Saúde da Família (NASF). A integração de todos os atores sociais - estudantes da área da saúde, profissionais e comunidade - é fundamental para o engajamento no planejamento de propostas de intervenção, para a abordagem multidisciplinar e para a contemplação dos objetivos previstos pelo PPLS.

Após vivenciarem os momentos do PPLS em sala de aula, foi proposto aos estudantes uma atividade nos serviços de saúde no qual passariam a atuar como facilitadores do processo de planejamento local. Os cenários de saúde foram três Unidades de Atenção Primária em Saúde localizadas na zona urbana de Fortaleza-CE e um Centro de Atenção Psicossocial 
(CAPS). Participaram desse momento profissionais da equipe multiprofissional de saúde atuantes nos referidos serviços. Em um primeiro momento, houve uma reunião entre os estudantes e as equipes multiprofissionais com a supervisão dos professores, com o intuito de realizar identificação e formulação dos problemas que seriam abordados no plano de ação a ser criado.

A ideia inicial era que os estudantes mediassem todos os passos do PPLS com as equipes de saúde no decorrer de dois dias e apresentassem um relato de experiência em sala de aula. Contudo, somente foi possível realizar a primeira reunião, pois a necessidade de isolamento social em decorrência da pandemia COVID-19 impediu a continuidade da atividade. Como alternativa foi solicitado que os estudantes, a partir da construção coletiva mediada, na primeira reunião idealizassem um plano de ação com ações que estivesse dentro de sua governabilidade. Esta atividade foi realizada de forma online pelos estudantes e teve como produto final uma apresentação em slides.

Os planos de ação criados abordaram as seguintes temáticas: baixa participação da comunidade nas atividades do conselho local; quebra de vínculo entre profissionais de saúde e os usuários do CAPS; elevados casos de ansiedade e depressão entre a população adulta, em geral com 40 anos ou mais, no território da UAPS; e insuficiência da sala de espera da UAPS.

A atuação dos estudantes como facilitadores promoveu a aprendizagem sobre a gestão de conflitos, a construção de consensos e a capacidade de proposição coletiva de propostas para superação de problemas. Assim, a experiência dos acadêmicos foi de suma importância para uma futura atuação no cenário do SUS.

A possibilidade de os alunos vivenciarem momentos de planejamento e programação em saúde, mediante as experiências práticas nos serviços que estiveram envolvidos ao longo da disciplina, garantiu a concretização dos ensinamentos ministrados dentro de sala de aula. A integração ensino-serviço permite uma maior consolidação do conteúdo e uma ampliação do seu entendimento dentro do contexto da saúde coletiva, fator que contribui para uma elucidação mais clara da aplicação dos conceitos e dos planos de gestão e organização na vida do profissional médico e da atenção à saúde (CAVALCANTE et al., 2017).

Apesar de todas as atividades terem buscado uma incursão teórico-prática do planejamento na gestão em saúde, na avaliação final da disciplina foi referido pelos estudantes, como sugestão, a necessidade de abordar com mais ênfase o planejamento no exercício da medicina, além de realizar mais atividades nos serviços de saúde. Essa sugestão pode se relacionar ao desafio de tornar as disciplinas relacionadas à saúde coletiva atrativas para os estudantes do curso de medicina, uma vez que há uma tendência em valorizar as 
disciplinas direcionadas às especialidades médicas em detrimento daquelas que enfocam a competência do médico dentro do sistema de saúde de forma mais abrangente, com ênfase na compreensão do todo social, biológico e ambiental (CUSTÓDIO et al., 2019).

\section{Considerações finais}

As atividades desenvolvidas estimularam a colaboração e o papel ativo do estudante na aprendizagem, além de promoverem uma aproximação do contexto vivenciado pelos gestores no âmbito do Sistema Único de Saúde, a partir da análise de problemas vivenciados no âmbito da atenção primária em saúde e em nível hospitalar. Houve ênfase no planejamento estratégico situacional e na importância da prática dialógica na proposição de ações.

A sugestão dos estudantes, direcionada à ampliação da abordagem focada na importância do planejamento na prática médica, sinaliza para o desafio do reconhecimento da formação em saúde coletiva focada no ser biopsicossocial e nas relações humanas estabelecidas no processo de trabalho.

O presente relato de experiência fornece subsídios para abordagem do planejamento em saúde na formação de profissionais para atuação no SUS, fornecendo as bases para a aplicação do planejamento como ferramenta de gestão tanto da atenção primária quanto na atenção hospitalar.

\section{REFERÊNCIAS}

BRASIL. Ministério da Saúde. Planejamento em saúde e práticas locais. Rio de Janeiro, 2004. Unidade de aprendizagem 3: módulo 6.

BRASIL. Ministério da Saúde. Política de formação e desenvolvimento para o SUS: caminhos para a educação permanente em saúde. Brasília, DF, 2003.

BRASIL. Resolução CNE/CES n. 4, de 7 de novembro de 2001. Institui diretrizes curriculares nacionais do curso de graduação em medicina. 2001. Diário Oficial [da] República

Federativa do Brasil: Seção 1, Brasília, DF: Poder Executivo, p. 38, 9 nov. 2001.

BRASIL. Resolução n. 3, de 20 de junho de 2014. Institui diretrizes curriculares nacionais do curso de graduação em medicina e dá outras providências. Diário Oficial [da] República Federativa do Brasil: Seção 1, Brasília, DF: Poder Executivo, p. 8-11, 23 jun. 2014.

CAVALCANTE, T. M. et al. Uma experiência de integração ensino, serviço e comunidade de alunos do curso de graduação em medicina na atenção básica no município de Maceió.

Revista Ciência Plural, v. 3, n. 3, p. 69-80, 2017. 
CUSTÓDIO, J. B. et al. Desafios associados à formação do médico em saúde coletiva no curso de medicina de uma universidade pública do Ceará. Revista Brasileira de Educação Médica, v. 43, n. 2, p. 114-121, 2019.

FENILI, R.; CORREA, C. E. G.; BARBOSA, L. Planejamento estratégico em saúde: ferramenta de gestão para o complexo de regulação em saúde. Revista Eletrônica Gestão e Saúde, v. 8, n. 1, p. 18-36, 2017. Disponível em:

https://dialnet.unirioja.es/servlet/articulo?codigo=5821299. Acesso em: 22 jun. 2020.

FUNGHETTO, S. S. et al. Perfil profissional tendo o SUS como base das diretrizes curriculares da área da saúde no processo avaliativo. Saúde em Redes, v. 1, n. 3, p. 103-120, 2015 .

GIL, C. R. R.; LUIZ, I. C.; GIL, M. C. R. Gestão pública em saúde: a importância do planejamento na gestão do SUS. São Luís: EDUFMA, 2016. Unidade 3.

GOMES, R. M.; BRITO, E.; VARELA, A. Intervenção na formação no ensino superior: a aprendizagem baseada em problemas (PBL). Interacções, v. 12, n. 42, p. 44-57, 2016.

JUNGES, J. R.; BARBIANI, R.; ZOBOLI, E. L. C. P. Planejamento estratégico como exigência ética para a equipe e a gestão local da atenção básica em saúde. Interface Comunicação, Saúde, Educação, v. 19, n. 53, p. 265-274, 2015.

LACERDA, J. T. et al. Planejamento em saúde. 2. ed. Florianópolis: Universidade Federal de Santa Catarina, 2013. Gestão de assistência farmacêutica: eixo 2: serviços farmacêuticos: módulo transversal. Disponível em: https://ares.unasus.gov.br/acervo/handle/ARES/3498. Acesso em: 17 jun. 2020.

MARTINS, A. C.; FALBO NETO, G.; SILVA, F. A. M. Características do tutor efetivo em ABP: uma revisão de literatura. Revista Brasileira de Educação Médica, v. 42, n. 1, p. 105114, 2018.

SANTOS JUNIOR, C. J. et al. Educação médica e formação na perspectiva ampliada e multidimensional: considerações acerca de uma experiência de ensino-aprendizagem. Revista Brasileira de Educação Médica, v. 43, n. 1, p. 72-79, 2019.

SILVA, A. L. F. et al. Saúde e educação pelo trabalho: reflexões acerca do PET-Saúde como proposta de formação para o Sistema Único de Saúde. Interface - Comunicação, Saúde, Educação, v. 19, n. 1, p. 975-984, 2015.

SILVA, R. E. B. G.; RAMALHO, A. P. Q.; SOUZA, C. C. O. Oficinas de planejamento em saúde na disciplina de saúde coletiva: relato de experiência. Revista de Graduação USP, São Paulo, v. 3, n. 2, p. 87-91, 2018.

UZÊDA, A. A. et al. Diagnóstico e prevenção da dengue em uma área de cobertura da estratégia saúde da família. Revista de Saúde Coletiva da UEFS, Santana, v. 7, n. 2, p. 21 34, 2017. 


\section{Como referenciar este artigo}

LIMA, I. C. V.; PEIXOTO, M. G. B.; SCHWERMANN, L. P.; SILVA, D. L.; MAIA, D. C. G. Construções coletivas na formação médica sobre planejamento em saúde. Temas em Educ. e Saúde, Araraquara, v. 16, n. 2, p. 720-734, jul./dez. 2020. e-ISSN 2526-3471. ISSN 1517-7947. DOI: https://doi.org/10.26673/tes.v16i2.13823

Submetido em: 21/04/2020

Revisões requeridas: 15/07/2020

Aprovado em: 20/07/2020

Publicado em: 27/08/2020 